\title{
A Review on Composition, Biological Significance of Plants Based On Medicinal and its Uses as Food on Human Nutrition
} \author{
Muhammad Ahmad', Zaigham Abbas ${ }^{6}$ \\ ${ }^{1}$ College of Food Science and Technology, Huazhong Agricultural University, China \\ ${ }^{2}$ Department of Agronomy, University of Agriculture, Faisalabad \\ ${ }^{3}$ Institute of Food Science and Nutrition, Bahauddin Zakariya University, Multan, Pakistan \\ ${ }^{4}$ Department of Botany, University of Agriculture, Faisalabad \\ ${ }^{5}$ Department of Plant Pathology, University of Agriculture, Faisalabad \\ ${ }^{6}$ National Institute of Food Science and Technology, University of Agriculture, Faisalabad
}

Muhammad Burhan Khan Tareen ${ }^{1}$, Abid Hussain ${ }^{2 *}$, Aleena Alam$^{4}$, Sahar $\mathrm{Haq}^{3}$, Muhammad Bilal Rana ${ }^{3}$, Abdul Rauf ${ }^{4}$,

DOI: $10.36348 /$ sjmps.2021.v07i01.008

| Received: 19.11.2020 | Accepted: 03.12.2020 | Published: 16.01.2021

*Corresponding author: Abid Hussain

\section{Abstract}

Most important medicinal plant is use as source of food in the world. It is necessary to understand the detection as well as chemical activities and other biochemical activities of potential compounds in medicinal plants. Medicinal plants are used as a source of the medicinal because it contains proteins as well as carbohydrates and important minerals needed for the body. Medicinal plants also possess the several chemical compounds due to which major diseases have been treated with special treatment of medicinal plants as compared to their plants. The presence of antioxidants that are found in rich amount in the external part of medicinal plants also leads to the various benefits. Medicinal plants contain a variety of compounds that are principally active and work against the free radicals. Out of potentially active compounds in the medicinal plants, antioxidants are the most important of all the compounds. The presence of the compounds in the inner as well as the outer portion of the medicinal plants makes it make antioxidants against the free radicals. These are the flavonoids that are showing the overall activities in the medicinal plants responsible for the blockages of the free radicals. Keywords: Medicinal, Free radicals, chemical compounds, flavonoids, diseases.

Copyright (C) 2020 The Author(s): This is an open-access article distributed under the terms of the Creative Commons Attribution 4.0 International License (CC BY-NC 4.0) which permits unrestricted use, distribution, and reproduction in any medium for non-commercial use provided the original author and source are credited.

\section{INTRODUCTION}

Medicinal plants are the most growing vegetable and used as source to treat various disease in the world and exhibits many compounds such as volatile with property of evaporation and some compounds that do not pass though evaporation. It is necessary to understand the detection as well as chemical activities and other biochemical activities of such compounds particularly in the field of biomedical sciences. There are many types of plants that show differences in physical properties such as changing colour of medicinal plants shows many varieties of medicinal plants. Important features of medicinal plants included flavor and have special types of compounds [1].

There are the certain compounds that are showing the main bioactivities against the bacteria, free radicals as well as the parasites. The presence of the potential compounds in the inner as well as the outer skin of the medicinal plants responsible for antioxidant activity against the free radicals [2-5]. These are the flavonoids that are showing the overall activities in the inner portion of medicinal plants and responsible for the blockages of the chemicals called free radicals. The main flavonoids are included the three compounds that are anthocyanin, which is involved the colour of the medicinal plants by pigmentation process [6]. If more of the anthocyanin is found in the outer part of the medicinal plants, then there is the high of the pigment called anthocyanin. The name of the major second type of the compound in the medicinal plants is the kaempferol which particularly binds with cells of the cancer ultimately it kills the cancer cells. So, medicinal plants are also used as a source of the medicinal biopharmaceutical plant for the purpose to treat the disease associated with cancer. The last compound in the medicinal plants is the quercetin that showing more of the composition of the medicinal plants [7].

\section{Composition and Role of Medicinal Plants}

Normally medicinal plants that are red in colour have maximum phenolics in addition to 
flavonoids along with demonstrate maximum antioxidant behavior amongst cultivars. Antioxidative as well as antiradical activity particularly revealed to extremely reliant on substance associated with phenolic compound. These free radicals are produced due to inhibition of antioxidants and also reduce the functional activities of antioxidants which become nonfunctional when there are high concentrations of free radicals. These free radicals also create the chemicals and other inhibitory signals that block the process of antioxidants and overall antioxidants lose their activity [8].

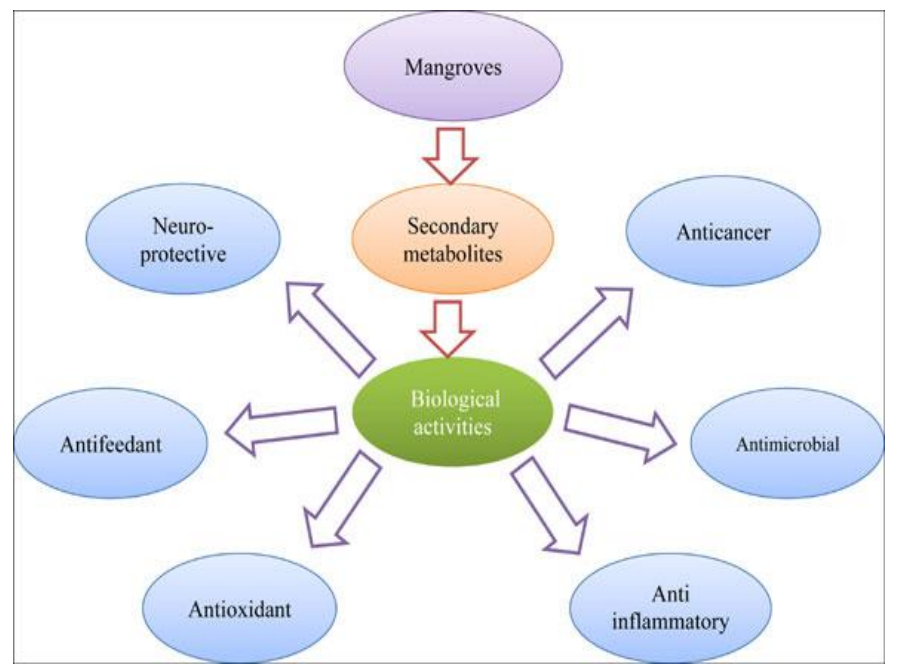

Fig-1: Shows the metabolites in medicinal plants

Antioxidants are found in rich amount in the external part of leaves of medicinal plants and therefore medicinal plants shows high activity against oxidants in their upper part of leaves. Antioxidants are found in low amount in the internal part of leaves of medicinal plants and medicinal plants shows low activity against the process of oxidation in their internal or inner part of leaves [9].

The major compound that found in medicinal plants is the flavonoid. This compound has been taken by using the Medicinal plants diet. The primary flavonoids that found in medicinal are quercetin that acts as antioxidant. Quercetin also makes strong binding to membrane of cell and protect the cell against injury associated with tissues also reduces the toxicity of certain drugs. The presence of antioxidants that are found in rich amounts in the external part of leaves of medicinal plants proves that medicinal plants has certain benefits in the medical field by improving medical activity of antioxidants and normal concentrations of antioxidants in medicinal plants has improving status of many diseases associated or increases by the process oxidation due to certain chemicals called oxidants. There is need to improve the biological and chemical behavior of antioxidants so that they might block the free radicals and ultimately oxidation and finally important to treat the cancer by blocking the cancerous cells which are produced due to increase in the concentration of oxygen[10].



Fig-2: Shows the derivatives of flavonoids with chemical structures 
There are certain compounds that are found in the major plant such as phenolics as well as polyphenols also called bioactive compounds majorly that are micronutrients taken by diet. Due to presence of these compounds, medicinal plants show biochemical properties against microbes. Therefore, growth of microbes can be inhibited due to presence of these compounds. It is important and key feature of medicinal plants that when it passes through the process of extraction extract obtained shows activity against microbes [11].

A lot of medicinal plants have been used to treat significant diseases caused by the bacteria. The main functions of the medicines obtained from the plants have less harmful effects on the body as compared by using the chemicals and drugs. There are many chemicals as well as drugs that are used to target the cells of bacteria. The main and biologically functions of these chemicals to decrease the level of growth of the specific bacteria. But there are many harmful effects of using the chemicals and drugs to decease the growth of the harmful bacteria. The specific type of chemicals as well as drugs kills both the cells of bacteria and also the cells of the body that helps to fight against the variety of specific type of bacteria. Bacteria also showing increase the resistance against specific chemicals and drugs. As results of this increase in the resistance, more useful medicinal plants needed to study for fight them by attacking the cells of bacteria [12].

There are the certain causes of the hemolysis that occurs in cells of the blood. These reasons are the presence of the harmful bacteria in the large concentrations, the major parasite such as any type of the plasmodium and any of the disease that associated with the genetics such as the sickle cell anemia. These are the conditions in which lysis of the cells of blood occurs that significantly releases the protein called hemoglobin into the cells. This type of the protein is involved in transport of certain materials such the transport or to carry the gas called oxygen and majorly supplies it properly to the different and major parts of the body by the process that follows the diffusion. The other factors that contributed in causes of the lysis of the cells of the blood might be certain chemicals that produced as a inhibitory agent to stop the various reaction of the cells of the body by killing the normal cells of the blood. It is needed to inhibit the chemicals that might be reason of the causes of the lysis of the cells of the blood [12].

The type of the bacteria that is involved in the lysis of the cells of the blood particularly RBCs is the staphylococcus. This type of bacteria once enters into the any of the cell of the body, then grows as well as multiply the cells that are the part of its body. It then finds the proper space of host for entering the cells of the blood and stays here for the prolonged time. As a result of this reaction that occurs in the particular cell, severe type of the reaction that also leads to the release the hemoglobin to the specific part of the cell such as the cytoplasm. Then the protein that has been released and remains the nonfunctional due to destruction of the cells of the RBCs. This type of the bacteria usually speared only by the air through the contact with person that has been infected with this bacteria. It also causes the cough when enter the cells of the body and resultantly the damage of the cells of the body. There are certain chemicals that are medically used for inhibiting the growth of this type of the bacteria. One of these included chemicals are antibiotics that are used to inhibit their growth as well kills them properly [3, 14, 15].

Compounds in the medicinal plants also the show activity against the abnormal cells that are entrapped and ultimately kills by the compounds found in the inner portion of the Medicinal plants. Medicinals plants also involved in inhibiting the cancer or process of the spreading of the cancer in blood by binding them. When saponins effectively binds to the abnormal WBCs, then a reaction that occurs in the body called immune response. This type of the response also depends on the concentrations as well as structure of the saponins. If there is the more of the concentrations of the saponins, then there are less concentrations of the abnormal type WBCs. But in other way, if there is less concentrations of the concentrations of the saponins, then there would of more concentrations of the abnormal type of WBCs. It also leads to the cancer in blood $[16,17]$.

Medicinal plants also possess the several properties and chemical elements due to which major diseases have been treated with special treatment of medicinal plants $[18,19]$. It is easily stored for the long time and no wastage or destruction of Medicinal plants occurs after storage in proper place [20]. It also works against the infections caused by several species of the bacteria that attack on cells of body. Medicinal plants are used as a source of commonly used food. In the world [21, 22, 23]. It gains more important as compared with other plants that are used to treat the diseases associated with metabolism. It contains the flavonoids, proteins as well as carbohydrates. It is used to treat large number of diseases by the potential activities such as antimicrobial and cytotoxic activities. It is also easily transported when ingested with supplying of nutrients and other major chemicals to the body by maintaining the reactions occurring in the body of the living system [24-27]. 


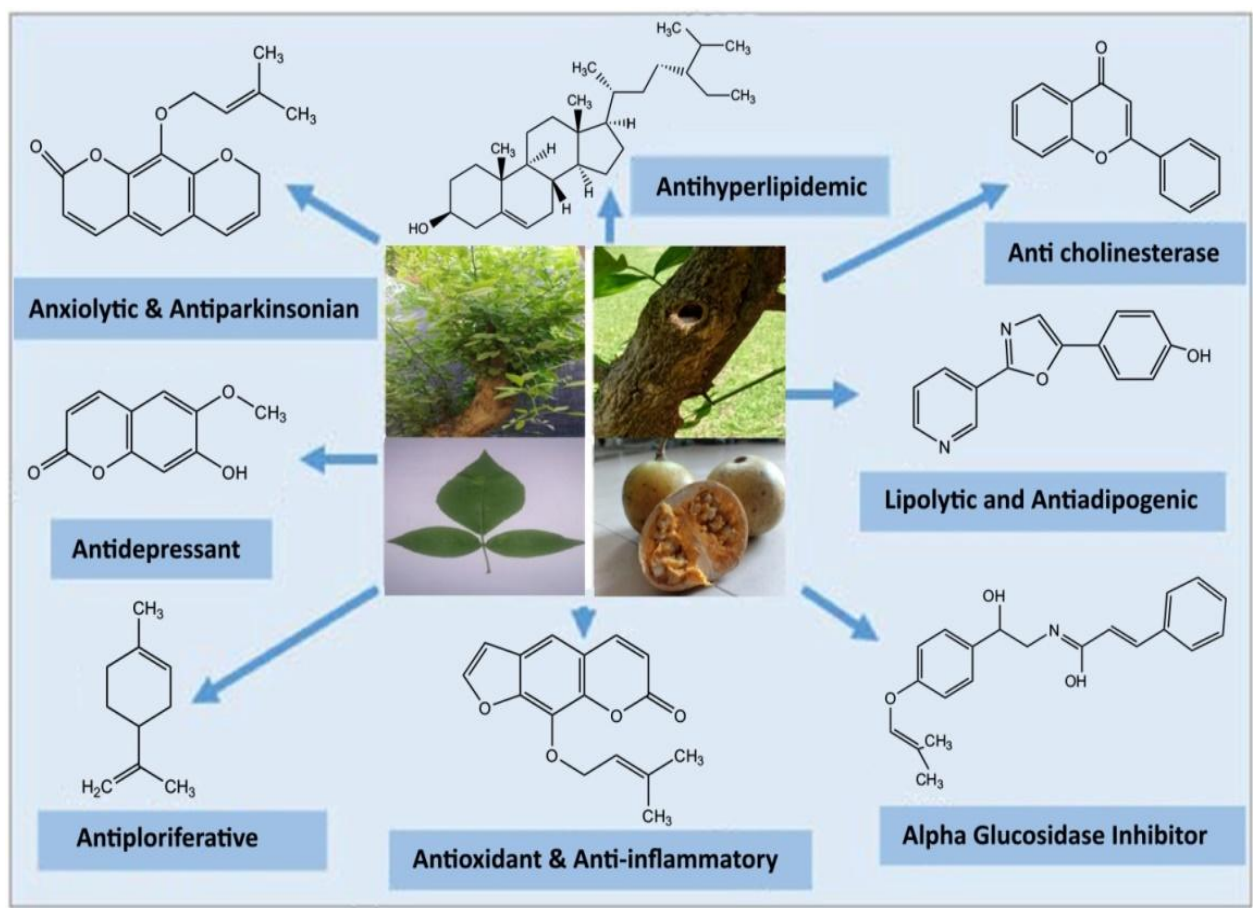

Fig-3: Shows the properties of medicinal plants

\section{CONCLUSION}

There are many diseases that have been treated by the using the medicinal plants. These diseases included the cancers, diabetes and many inflammatory diseases. These diseases are not completely treated yet with the medicines that are used as the chemicals. Many plants contain variety of compounds such as the flavonoids that are not completely studied. This review helpful for the investigation of the novel compounds in many plants that are used to treat the large number of diseases as well as to understand the nature of compounds that reduce the production of the free radicals in the particular cells.

\section{REFERENCES}

1. Usman, G., Muhammad, N., Hamza, R., Usman, I., Ayesha, A., Saqib, U., \& Fatima, Q. (2019). A Novel Approach towards Nutraceuticals and Biomedical Applications. Scholars International Journal of Biochemistry, 2(10), 245-252.

2. Chopra, R. N., Nayar, S. L., \& Chopra, I. C. (1956). Glossary of Indian medicinal plants (Vol. 1, pp. 138-139). New Delhi: Council of Scientific \& Industrial Research.

3. Ahsan, M., Aslam, M., Akhtar, M. A., Azmi, U. R., Naeem, M., Murtaza, G., \& Shafiq, S. (2019). Effect of inoculation of three rhizobial strains on maize hybrids. Journal of Biodiversity and Environmental Sciences, 14(6), 168-177.

4. Naeem, A., Saddique, S., \& Chand, S. A. (2019). Advancement and Future Directions towards Herbal Treatment for Various Diseases.

5. Xu, D. P., Li, Y., Meng, X., Zhou, T., Zhou, Y., Zheng, J., \& Li, H. B. (2017). Natural antioxidants in foods and medicinal plants: Extraction, assessment and resources. International journal of molecular sciences, 18(1), 96.

6. Rafeeq, H., Ahmad, S., Tareen, M. B. K., Shahzad, K. A., Bashir, A., Jabeen, R., \& Shehzadi, I. Biochemistry of Fat Soluble Vitamins, Sources, Biochemical Functions and Toxicity.

7. Lajayer, B. A., Ghorbanpour, M., \& Nikabadi, S. (2017). Heavy metals in contaminated environment: destiny of secondary metabolite biosynthesis, oxidative status and phytoextraction in medicinal plants. Ecotoxicology and Environmental Safety, 145, 377-390.

8. Naeem, M., Ashraf, A., Safdar, H. M. Z., Khan, M. Q., Rehman, S. U., Iqbal, R., ... \& Ahmad, G. Biochemical changes in patients with chronic kidney failure in relation to complete blood count and anemia.

9. Hussain, A., Rafeeq, H., Asghar, A., Ullah, S., Imtiaz, U., Ullah, H., \&amp;amp; Ilyas, M. D. Combined inhibitory potential of Ammonium thiosulphate and 2-chloro- (trichloromethyl) pyridine on ureases activities.

10. Ribeiro, R. V., Bieski, I. G. C., Balogun, S. O., \& de Oliveira Martins, D. T. (2017). Ethnobotanical study of medicinal plants used by Ribeirinhos in the North Araguaia microregion, Mato Grosso, Brazil. Journal of ethnopharmacology, 205, 69102.

11. Muhammad, N., Muhammad, M., Asim, U., Siraj, A., Ghafoor, A., Jabir, A., Sayed, Jasim, R. Z., Muhammad, Z. H., Tania, Z., Irfan, K. (2019). New trends in removing toxic metals from drinking and wastewater by biomass materials and advanced membrane technologies September. 
12. Rouhi-Boroujeni, H., Heidarian, E., RouhiBoroujeni, H., Deris, F., \& Rafieian-Kopaei, M. (2017). Medicinal plants with multiple effects on cardiovascular diseases: A systematic review. Current pharmaceutical design, 23(7), 9991015.

13. Rafeeq, H., Arshad, M. A., Amjad, S. F., Ullah, M. H., Muhammad, H., Imran, R. K., ... \& amp; amp; Ajmal, H. Effect of Nickel on Different Physiological Parameters of Raphanus Sativus.

14. Rafeeq, H., Tanvir, K., Khan, M. A. B., Basit, I., Ul, Q., Ain, F. F., ... \& amp; amp; Siddique, S. An Effective Approach towards Heavy Metals and their Effects on Different Organs of the Body.

15. Hussain, A., Nashat, N., Liaqat, A., Waheed, M., Aslam, M., \& Asif, N. A Comprehensive Review on Diabetic Retinopathy and Mental Disorders.

16. Maqsood, S., Qadir, S., Hussain, A., Asghar, A., Saleem, R., Zaheer, S., \& Nayyar, N. (2020). Antifungal Properties of Copper Nanoparticles against Aspergillus niger.

17. Ahmad, I., Khan, S., Naeem, M., Hayat, M., Azmi, U. R., Ahmed, S., ... \& Irfan, M. (2019). Molecular Identification of Ten Palm Species using DNA Fingerprinting. Int. J. Pure App. Biosci, 7(1), 4651.

18. Eddouks, M., Ajebli, M., \& Hebi, M. (2017). Ethnopharmacological survey of medicinal plants used in Daraa-Tafilalet region (Province of Errachidia), Morocco. Journal of ethnopharmacology, 198, 516-530.

19. Hamza, R., Irha, B., Rizwana, J., Iqra, S., Kanwal, S., Sobia, T., Qurat ul Ain, N., Hafiza M. R. (2020). Biochemistry of Water Soluble Vitamins, Sources, Biochemical Functions and Toxicity. Scholars International Journal of Biochemistry.

20. Rafeeq, H., Ahmad, S., Tareen, M. B. K., Shahzad, K. A., Bashir, A., Jabeen, R., \& Shehzadi, I.
Biochemistry of Fat Soluble Vitamins, Sources, Biochemical Functions and Toxicity.

21. Naeem, M., Ali, J., Hassan, M. Z., Arshad, B., Rao, M. H. I., Sarmad, M. S. K., ... \& Hussain, M. U. Novel Approach towards DNA Barcoding as a Tool in Molecular Biology and Biological Activities of Cyclotides with Particular Emphasizes at Molecular Level.

22. Dodeigne, C., Thunus, L., \& Lejeune, R. (2000). Chemiluminescence as diagnostic tool. A review. Talanta, 51(3), 415-439.

23. Shafiq, S., Adeel, M., Raza, H., Iqbal, R., Ahmad, Z., Naeem, M., \& Azmi, U. R. (2019). Effects of Foliar Application of Selenium in Maize (Zea Mays L.) under Cadmium Toxicity. In Biological Forum-An International Journal, 11(2), 27-37.

24. Naeem, M., Hayat, M., Qamar, S. A., Mehmood, T., Munir, A., Ahmad, G., ... \& Hussain, A. (2019). Risk factors, genetic mutations and prevention of breast cancer. Int. J. Biosci, 14(4), 492-496.

25. Anand, U., Jacobo-Herrera, N., Altemimi, A., \& Lakhssassi, N. (2019). A comprehensive review on medicinal plants as antimicrobial therapeutics: potential avenues of biocompatible drug discovery. Metabolites, 9(11), 258.

26. Aanouz, I., Belhassan, A., El-Khatabi, K., Lakhlifi, T., El-Ldrissi, M., \& Bouachrine, M. (2020). Moroccan Medicinal plants as inhibitors against SARS-CoV-2 main protease: Computational investigations. Journal of Biomolecular Structure and Dynamics, 1-9.

27. Hazafa, A., Batool, A., Ahmad, S., Amjad, M., Chaudhry, S. N., Asad, J., \& Ghani, U. (2020). Humanin: A mitochondrial-derived peptide in the treatment of apoptosis-related diseases. Life Sciences, 118679. 